\title{
Membrane fouling of forward osmosis in dewatering of soluble algal products: Comparison of TFC and CTA membranes
}

\author{
Jing-Ya Li ${ }^{\mathrm{a}}$, Zhi-Yi Ni ${ }^{\mathrm{a}}$, Zong-Yao Zhou ${ }^{\mathrm{b}}$, Yun-Xia Hu ${ }^{\mathrm{b}}$, Xin-Hua Xu ${ }^{\mathrm{a}}$, Li-Hua Cheng ${ }^{\mathrm{a}, *}$

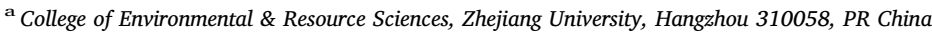 \\ b Yantai Institute of Coastal Zone Research, Chinese Academy of Sciences, Yantai 264003, PR China
}

\section{A R T I C L E I N F O}

\section{Keywords:}

Soluble algal products (SAP)

Forward osmosis

Microalgae dewatering

Membrane fouling

Reverse salt diffusion

\begin{abstract}
A B S T R A C T
Forward osmosis (FO) has increasingly penetrated into traditional process, i.e. microalgae dewatering, to become one of the new energy saving technologies. However, FO membranes can be fouled by soluble algal products (SAP) and fouling behavior of the membrane is not clear due to the variety of SAP composition. In this work, two types of membranes including a self-made TFC and a commercial CTA, and three kinds of draw solutions including $\mathrm{NaCl}, \mathrm{MgCl}_{2}$ and $\mathrm{CaCl}_{2}$ were adopted to investigate the dewatering of SAP from microalgae of Chlorella vulgaris. The dependence of permeate flux and foulants composition on the membranes, membrane orientation and reverse salt diffusion were then compared for membrane fouling behavior. The results showed that TFC membrane exhibited higher water permeability but more loss of water flux in comparison with CTA. The SAP was inclined to be adsorbed by TFC membrane while adsorbate was easier to be removed by physical cleaning. By contrast, the pollutants accumulated on the membrane surface of CTA were much more irreversible. The interaction between SAP from feed solution and calcium cations from draw solution induced the formation of cake layer on the surface of TFC membrane while irreversible granular deposits of SAP were found accumulated on CTA membrane surface. Possible membrane fouling mechanism was finally discussed for better fabrication of anti-fouling forward osmosis membranes, thus to propel the integration of forward osmosis with traditional field of microalgae dewatering.
\end{abstract}

\section{Introduction}

Currently, energy crisis and water shortage have been considered as two challenges in the world along with population growth and urbanization $[1,2]$. Microalgae, owing to the coupling advantages of oil production and wastewater treatment, has become one of the most promising sources to handle the energy dependence and water scarcity $[3,4]$. Despite microalgae has many competitive advantages, it is well accepted that some challenges still remained to be addressed before large-scale microalgae production can be realized practically. For example, to separate and harvest algae cells from culture medium is one of the technical and economical bottlenecks to batch cultivation of microalgae [5].

Unlike conventional methods, for example centrifugation requires a considerable energy input due to the small size of algae cells (typically a few micrometers), the similar density of microalgae to water, and low algal concentration in the culture medium [6-8], membrane-based process is recently becoming one popular operation unit in bulk production of microalgae [9]. Various studies involved in membranes have been investigated for dewatering and concentration of microalgae cultures including microfiltration (MF), ultrafiltration (UF), and reverse osmosis (RO) [10-13]. Submerged membrane module has also been adopted into photobioreactors for not only microalgae cultivation but also nutrients removal from tertiary wastewater, thus to seek the reliability and applicability of the whole system $[14,15]$.

Unlike those conventional membrane processes, forward osmosis (FO) is recognized as an emerging membrane separation technology which has been potentially used to treat complex highly concentrated organic wastewater, such as landfill leachate, dyeing wastewater, anaerobic digester concentrate and liquid foods in the food industry [16-20]. Microalgae dewatering with FO has also been developed in the past few years for its low energy consumption and high efficiency [21]. However, during the process of microalgae dewatering, the fouling layers on the membrane surface could be formed by algal cells and gellike soluble algal products (SAP), hindering the membrane performance greatly. For example, Gu et al. [22] studied flux reduction using alginate as the model foulant and found that commercial TFC membrane showed greater fouling propensity compared to the CTA membrane.

\footnotetext{
* Corresponding author.

E-mail address: chenglihua@zju.edu.cn (L.-H. Cheng).
} 
Honda et al. [23] investigated flux recovery and foulants characteristics with a commercial CTA membrane for the concentration of Chlorella vulgaris. They observed that SAP was related to the irreversible fouling in active layer facing draw solution (AL-DS) mode. The SAP, released naturally by microalgae during the entire culturing process, was prone to be sticky on the membrane, making it serious for membrane fouling.

Actually, the composition of SAP is complicated with various components including carbohydrates, proteins, lipids, amino acids, peptides, organic phosphorus, enzymes, vitamins, and so on [24,25]. These macromolecules are also inclined to interact with inorganic salts from draw solution. For example, Ming et al. proposed that the complexation of calcium ions to bacterial extracellular polymeric substances (EPS) exacerbated the biofouling behavior of FO [26]. Larronde-Larretche et al. found that back diffusion of calcium ions could accelerate the excretion of carbohydrates thus reducing the algae dewatering efficiency $[5,27]$. Although these studies have shown some analysis for the effect of reverse diffusion of salts on the formation of foulants in FO process, reverse flux of salts and adsorption capacity of SAP on both TFC and CTA membranes have not been investigated for their fouling behavior simultaneously. In addition, fouling features of carbohydrates and proteins in SAP adsorbed onto different types of FO membranes were not clearly presented $[28,29]$.

In this study, TFC and CTA membranes were investigated not only on their water flux and reverse salt fluxes of three draw solutions, but also on pollutants characteristics accumulated on the membrane surface. The relationship between reverse salt flux, adsorption capacity of SAP and fouling behavior was finally explored to elucidate possible membrane fouling mechanism. The aim of this work is to provide theoretical evidence for better fabrication of anti-fouling forward osmosis membranes, thus to propel the integration of forward osmosis with traditional field of microalgae dewatering.

\section{Materials and methods}

\subsection{Microalgae cultivation}

Chlorella vulgaris (FACHB-36) was purchased from Freshwater Algae Culture Collection at the Institute of Hydrobiology (FACHB-collection, China). The monoculture was first cultivated with Selenite Enrichment (SE) medium in an artificial photobioreactor, the diameter and height of which was $20 \mathrm{~cm}$ and $40 \mathrm{~cm}$ with a working volume of $10 \mathrm{~L}$. Continuous light irradiation was provided at $50 \mu \mathrm{mol}$ photons $\mathrm{m}^{-2} \mathrm{~s}^{-1}$ and compressed air (vvm) was sparged into the reactor by an air pump at constant room temperature of $25 \pm 2{ }^{\circ} \mathrm{C}$. The concentration of algal broth was analyzed every two days using a visible spectrophotometer (HACH DR3900, USA) in a batch mode until C. vulgaris reached its stationary phase after 25 days of cultivation. The stock solution of SAP, filtered through $0.45 \mu \mathrm{m}$ glass fiber membrane (Xingya Purification Material Factory, China), was used as the feed solution for dewatering with FO.

\subsection{FO membranes}

The thin film composite membrane (TFC) made at Yantai Institute of Coastal Zone Research Chinese Academy of Sciences (Yantai, China) and cellulose triacetate membrane (CTA) purchased from Hydration Technology Innovations (HTI, USA) were used as representative FO membranes in this study. Both asymmetric membranes were composed of bilayer substrate. The TFC membrane prepared via the layer-by-layer assembly method had an active layer of polyamide and a support layer of polysulfone. By contrast, the CTA membrane, with polyester fabric embedded in the second layer to provide the mechanical strength, was characteristic of the excellent property of hydrophilicity. The FO membranes were placed either in active layer facing feed solution (ALFS) mode or active layer facing draw solution (AL-DS) mode to explore the corresponding fouling mechanism.
Basic membrane parameters including pure water permeability $(A)$, salt permeability $(B)$, and selectivity $(S)$ were measured following the reported method [30]. These parameters objectively represented the comparable performance of membranes. After attaining water flux $\left(J_{w}\right)$ and reverse salt flux $\left(J_{S}\right)$ using four concentrations of draw solutions, $A$, $B$ and $S$ were calculated according to the following equations [30]:

$$
\begin{aligned}
& J_{w}=A\left\{\frac{\pi_{D} \exp \left(-\frac{J_{W} S}{D}\right)-\pi_{F} \exp \left(\frac{J_{w}}{k}\right)}{1+\frac{B}{J_{w}}\left[\exp \left(\frac{J_{W}}{k}\right)-\exp \left(-\frac{J_{W} S}{D}\right)\right]}\right\} \\
& J_{S}=B\left\{\frac{C_{D} \exp \left(-\frac{J_{W} S}{D}\right)-C_{F} \exp \left(\frac{J_{W}}{k}\right)}{1+\frac{B}{J_{W}}\left[\exp \left(\frac{J_{W}}{k}\right)-\exp \left(-\frac{J_{W} S}{D}\right)\right]}\right\}
\end{aligned}
$$

where $C_{F}$ and $C_{D}$ represented the concentration of feed solution and draw solution, and $\pi_{F}$ and $\pi_{D}$ were the osmotic pressure of feed solution and draw solution, respectively; $k$ was the mass transfer coefficient of feed solute, and $D$ was the bulk diffusion coefficient of draw solute.

In order to understand the effect of surface charge of membranes on the adsorption of SAP, zeta potential analyzer (SurPASS, Anton Paar $\mathrm{GMbH}$, Australia) was applied to quantitatively characterize the charge property (positive or negative) and charge density at the membrane interface. Wet membrane samples were first soaked in $1 \mathrm{mM} \mathrm{KCl}$ solution for $1 \mathrm{~h}$ before it was attached to an adjustable gap cell. Membrane samples and membrane module were then thoroughly rinsed for testing. The $\mathrm{pH}$ of solution was adjusted to 7 using $0.1 \mathrm{M} \mathrm{HCl}$ and $0.1 \mathrm{M} \mathrm{NaOH}$, and test temperature was kept at $25^{\circ} \mathrm{C}$.

\subsection{Experimental setup for FO membrane fouling}

All FO membrane fouling experiments were conducted using a custom-made membrane filtration module. The effective membrane surface area of membrane module was $3 \times 10^{-3} \mathrm{~m}^{2}(10 \mathrm{~cm} \times 3 \mathrm{~cm})$ with the cross-flow rate of $5.5 \mathrm{~cm} \mathrm{~s}^{-1}$ on both sides. Draw solutions including $\mathrm{NaCl}, \mathrm{MgCl}_{2}$ and $\mathrm{CaCl}_{2}$ were used to investigate characteristics of membrane fouling induced by different cations. The concentration of each draw solution was adjusted to achieve a situation that the osmotic pressure was almost at the same level with $1 \mathrm{M} \mathrm{NaCl}$ solution. For feed solution, the SAP of microalgae was diluted with deionized water to contain $20 \mathrm{mgCL}^{-1}$ of dissolved organic carbon (DOC) in order to ensure the same initial conditions of each experiment. $1 \mathrm{~L}$ feed solution and $3 \mathrm{~L}$ draw solution were circulated for $10 \mathrm{~h}$ using two peristaltic pumps (Longer pump BT300-2J, China). The temperature of both solutions were kept at $25 \pm 1{ }^{\circ} \mathrm{C}$ by two heating rods (GOL-25W, China). The weight of feed solution was monitored in real time for the determination of permeate water flux from feed solution to draw solution.

The FO system was cleaned completely before every cycle experiment was carried out. Cleaning of the whole system comprised two steps. The membrane module was flushed first with deionized (DI) water at a crossflow velocity of $11 \mathrm{~cm} \mathrm{~s}^{-1}$ for $0.5 \mathrm{~h}$ for three times. DI water was then circulated through the system for $1 \mathrm{~h}$ after the assembly of a new membrane coupon.

\subsection{Analysis of foulants}

Feed samples were collected before and after experiments to determine their DOC, carbohydrates and proteins content, respectively. These measurements were carried out after the filtration through $0.45 \mu \mathrm{m}$ glass fiber membrane in order to ensure all data represented the soluble content. The DOC content was quantified by TOC analyzer (Shimadzu TOC-VCPH, Japan) [31]. For carbohydrates measurement, the method of phenol-sulphuric acid with glucose as the standard was used [32]. Proteins content was measured by modified Lowry method, in which the bovine serum albumin (Sigma Aldrich, China) was used as 
the standard [33].

At the end of each FO experiment, the membrane subsection of $2 \mathrm{~cm} \times 2 \mathrm{~cm}$ was cut from the center of membrane immediately and placed in a centrifuge tube containing $26 \mathrm{~mL}$ ultrapure water with $100 \mu \mathrm{L}$ of $0.1 \mathrm{M} \mathrm{HCl}$. The test tube was then sonicated in a flask filled with ice in fifteen 60-s cycles to remove organic compound from the membrane. After retaining the resultant solution, the concentration of DOC, carbohydrates and proteins was determined respectively, and calculation of the content of the whole membrane was conducted according to the following equation:

$m=C \times V \times A_{0} / A$

where $\mathrm{m}$ represented the mass of DOC, carbohydrates and proteins content respectively, $\mathrm{C}$ represented the mass concentration of DOC, carbohydrates and proteins respectively; $\mathrm{A}_{0}$ and $\mathrm{A}$ were the subsection area of membrane sample and effective membrane area. Theoretically, the DOC, carbohydrates and proteins content in the feed solution before and after FO experiments and that retained on membrane followed the following equation:

$\mathrm{m}_{\mathrm{b}}=\mathrm{m}_{\mathrm{a}}+\mathrm{m}_{\mathrm{r}}+\mathrm{m}_{\text {loss }}$

where $\mathrm{m}_{\mathrm{b}}$ and $\mathrm{m}_{\mathrm{a}}$ represented the content of DOC, carbohydrates and proteins in the feed solution before and after FO experiments respectively. It is noteworthy that the DOC, carbohydrates and proteins content which could be washed from the membrane by ultrasound was defined as reversible part of $\mathrm{m}_{\mathrm{r}}$; those could not be washed from the membrane together with those insolubles formed on membrane surface and then were washed into feed solution by hydraulic scouring during the period of dewatering, were collectively referred to as $\mathrm{m}_{\text {loss }}$.

Surface morphologies of membranes were further visualized with the cold cathode field emission scanning electron microscopy (FESEM, SU8010, HITACHI, Japan). The naturally dried membrane sample was carefully mounted on the stainless steel stub using a conductive tape respectively, followed by gold sputtering upon all the membrane samples [34].

\section{Results and discussion}

\subsection{Membrane performance parameters}

The five representative performance parameters including pure water permeability $(A)$, salt permeability $(B)$, selectivity $(S)$, reverse salt flux of draw solute and zeta potential for both TFC and CTA membranes were summarized in Table 1 . The $A$ value of TFC membrane was about four times that of the CTA membrane. The attractive water permeability of this TFC-based membrane was comparative to the commercial TFC membranes of HTI $[27,35]$. The superior performance was consistent with the fact that the TFC membrane used in this study had a support structure that was more porous than CTA. The porous layer reduced internal concentration polarization (ICP) in the membrane thus greatly improved the water flux [23]. In addition, it was clear to find that the selectivity of TFC in this work was much lower than that of CTA. Such a decrease in salt selectivity conformed to the intrinsic relationship between $A$ and $S$, where the increase in water permeability was accompanied by a rapid decline of salt selectivity [26].

Reverse salt fluxes of $\mathrm{NaCl}, \mathrm{MgCl}_{2}$, and $\mathrm{CaCl}_{2}$ with DI water as feed solution revealed the difference in back diffusion abilities of these three inorganic salts. Since the reverse salt flux was changed along with $S$, as shown in Table 1, reverse salt fluxes of TFC membrane were higher than those with CTA membrane. For TFC membrane, reverse salt fluxes in AL-DS mode were 1.4 - 1.8 times than those under AL-FS mode for each type of salt. By contrast, there were no significant variations between both modes in terms of their back diffusion for CTA membrane.

As shown in Table 1, both membranes showed negative potential and the TFC membrane was much more negative than CTA. According to Elimelech et al. [36], the surface electronegativity of TFC membrane

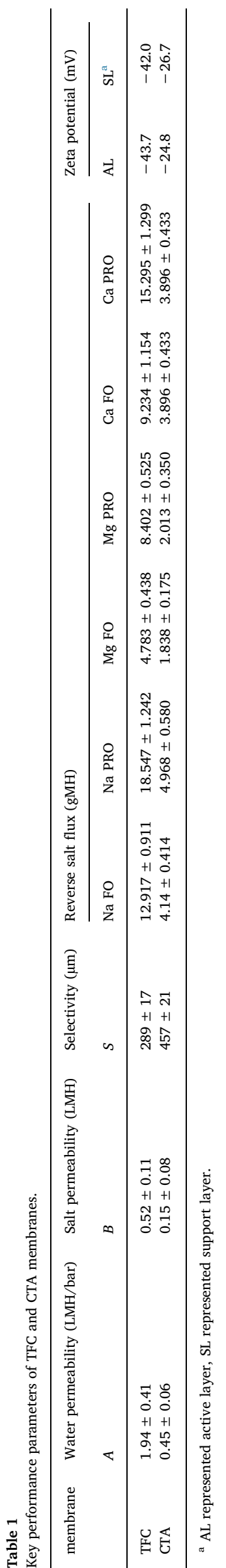



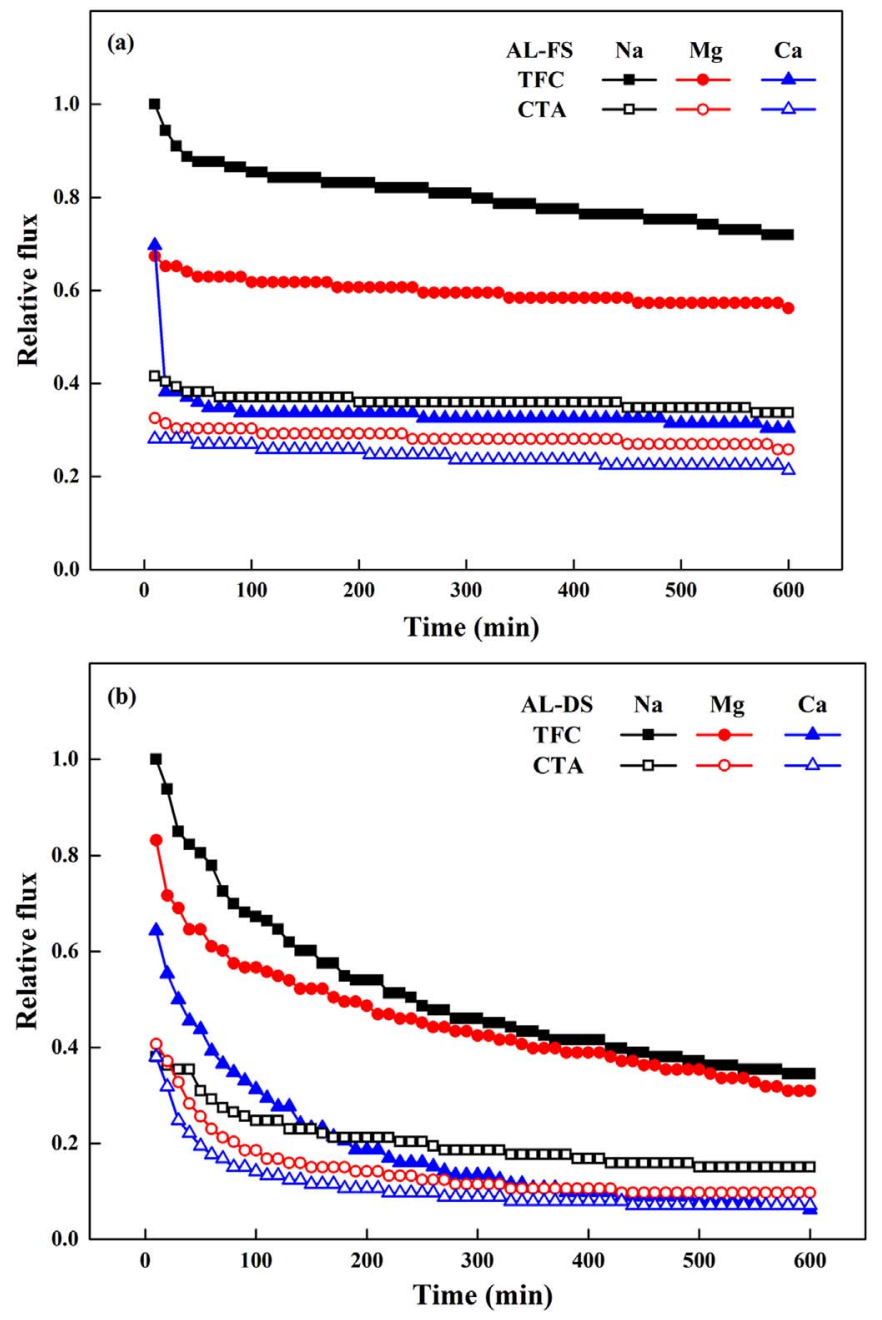

Fig. 1. Effect of membrane orientation and draw solution type on relative water flux for TFC and CTA membranes: (a) in AL-FS mode, (b) in AL-DS mode.

was caused by dissociation of carboxylic acid groups $\mathrm{R}-\mathrm{COOH}$ of the polyamide following $\mathrm{R}-\mathrm{COOH}=\mathrm{R}-\mathrm{COO}^{-}+\mathrm{H}^{+}$. Whereas for CTA membrane, the acetyl $\left(\mathrm{CH}_{3} \mathrm{CO}-\mathrm{R}\right)$ and hydroxyl $(\mathrm{R}-\mathrm{OH})$ groups did not dissociate in aquatic systems, so it was possible to form the negative surface charge due to the adsorption of electrolyte anions $\left(\mathrm{OH}^{-}\right.$and $\left.\mathrm{Cl}^{-}\right)$ during zeta potential measurement, and/or traces of acetic acid from acetylation and/or acidic functional additives during membrane fabrication. Since the pH of SAP solution was usually in the range of $7-8$, TFC membrane became more negative due to the ionization of carboxylic acid groups.

\subsection{Effect of SAP on water flux for TFC and CTA membranes}

The comparison of water flux behavior for membranes with different draw solutions in both AL-FS and AL-DS mode was demonstrated in Fig. 1. It was expected that TFC membrane exhibited higher water permeability than CTA. The initial fluxes were $1.5-2$ times higher in both modes of TFC, and final fluxes of TFC were also higher except for the test in AL-DS mode with $\mathrm{CaCl}_{2}$. It showed that the decline of water flux caused by $\mathrm{CaCl}_{2}$ was the most serious among the three draw solutions and it might relate to the specific fouling behavior of $\mathrm{CaCl}_{2}$.

As shown in Fig. 1, water flux decreased with time. All curves experienced a rapid decline followed by a level one. When the active layer of membrane was facing feed solution (AL-FS), the decline was developed within half an hour. The flux in AL-DS mode, by contrast, had a much longer and more rapid drop as a result of the stronger
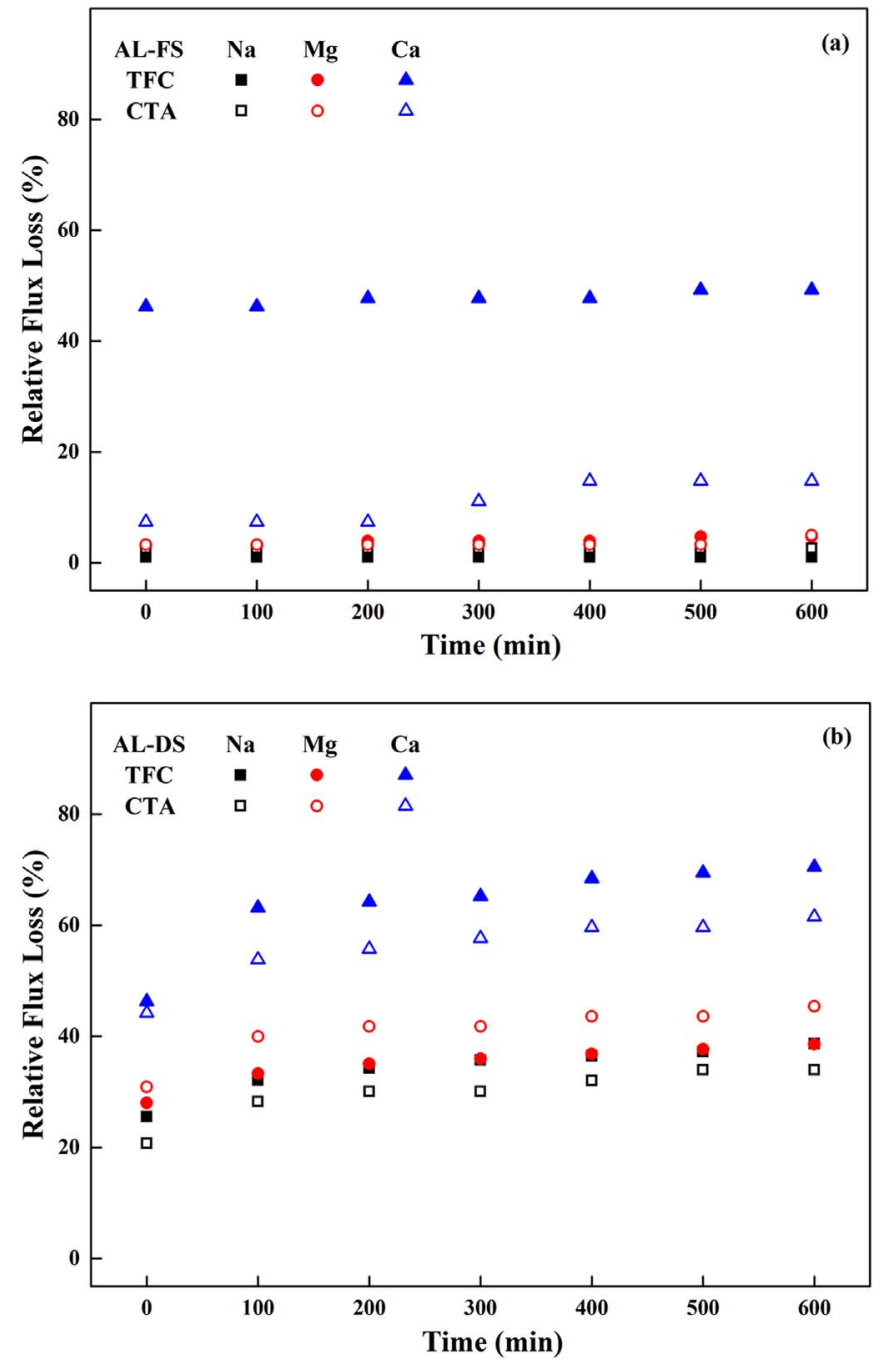

Fig. 2. Effect of membrane orientation and draw solution on relative water flux loss for TFC and CTA membranes: (a) in AL-FS mode, (b) in AL-DS mode. All relative water flux loss curves were corrected by baselines corresponding to each type of draw solutions and then normalized respectively.

combination of the foulants accumulation and dilution of draw solution. It seemed that for the purpose of maintaining high permeate water flux, it was much better to choose AL-FS mode for the application of microalgae dewatering.

Since water flux decline was in response to membrane fouling, the relative water flux loss was then investigated for a better understanding of membrane fouling. The relative water flux loss was corrected by subtracting the loss of DI water relevant to each type of draw solutions and then normalized respectively so that to reveal the net impact of SAP completely. As a result, no other loss was included like the dilution of draw solutions causing the reduction of osmotic pressure difference. As shown in Fig. 2, flux loss occurred mainly at the beginning of each test, suggesting the formation of foulants on membrane was a quick process. By contrast, the mode of AL-DS had a much more noticeable increase in the loss of flux during the whole experiment period, indicating the relatively severe membrane fouling. It was reported that the roughness characteristic of membrane support layer was inclined to adsorb foulants $[37,38]$. It was probably that not only the internal pore clogging but also cake layer formation contributed to the relatively severe membrane fouling in AL-DS mode [23]. Although the flux decline rate was different for both membrane orientations, their final loss followed almost the same order: TFC-CaCl ${ }_{2}>\mathrm{CTA}-\mathrm{CaCl}_{2}>\mathrm{CTA}-\mathrm{MgCl}_{2} \geq \mathrm{TFC}$ $\mathrm{MgCl}_{2}>$ TFC-NaCl $\geq \mathrm{CTA}-\mathrm{NaCl}$. In addition, the TFC membrane 

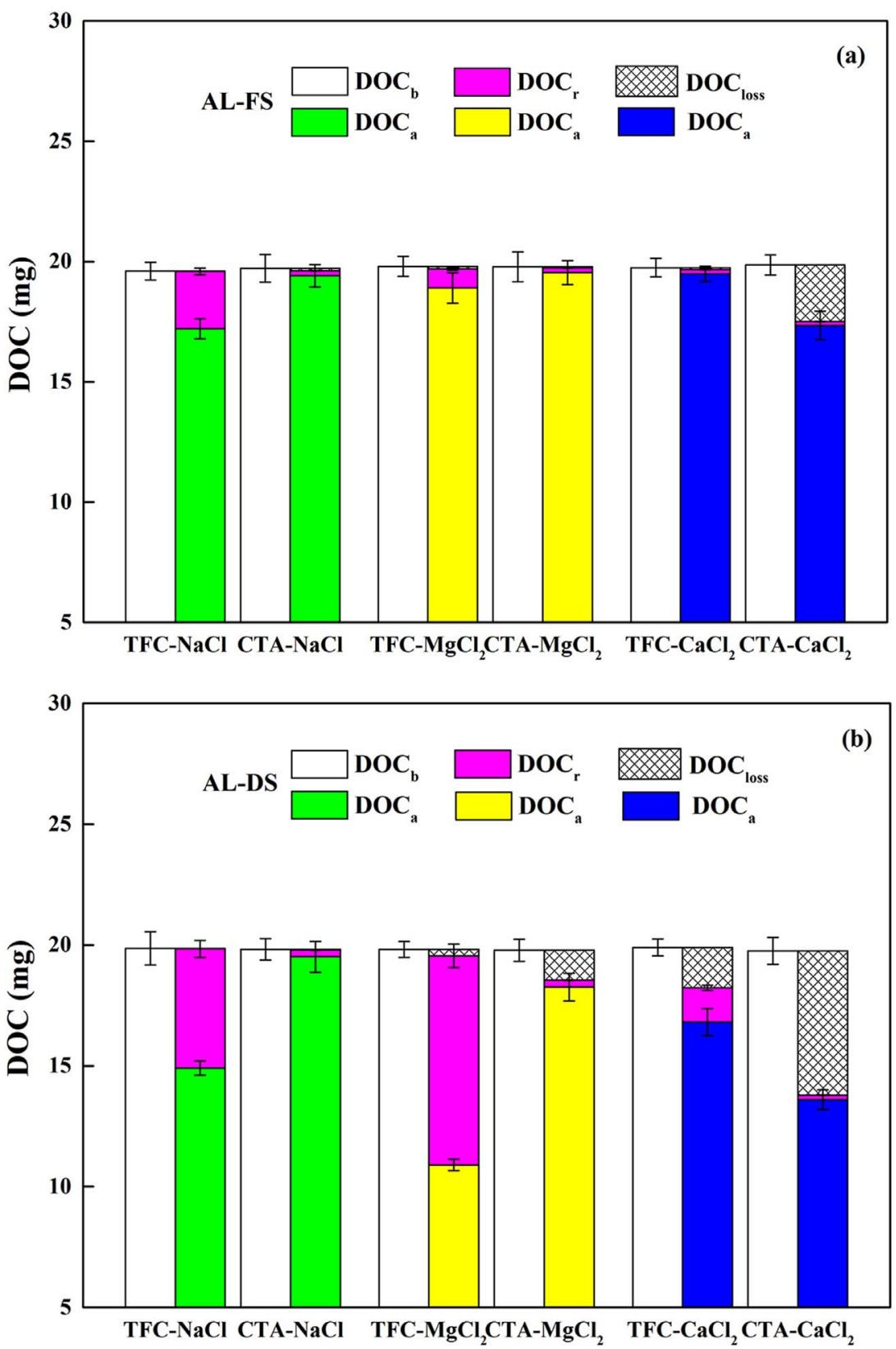

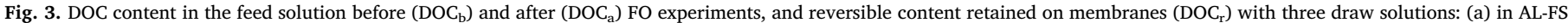
mode, (b) in AL-DS mode.

showed higher flux loss than CTA when $\mathrm{NaCl}$ and $\mathrm{CaCl}_{2}$ were used as draw solutions. Noting that the flux loss of CTA membrane was higher than that of the TFC membrane in AL-DS mode when $\mathrm{MgCl}_{2}$ was used as draw solution. It indicated that membrane fouling may be attributed to the possible synergistic effect of both membranes and draw solutions, and therefore foulants composition was further explored.

\subsection{Characteristics of membrane foulants}

To further investigate the foulants attracted onto membranes, each membrane coupon was washed by ultrasound after FO experiment. The DOC content in feed solution before $\left(\mathrm{DOC}_{\mathrm{b}}\right)$ and after $\left(\mathrm{DOC}_{\mathrm{a}}\right) \mathrm{FO}$ experiments and reversible content retained on membranes $\left(\mathrm{DOC}_{\mathrm{r}}\right)$ with different draw solutions in both AL-FS and AL-DS orientations were shown in Fig. 3. An interesting result was found that the $\mathrm{DOC}_{\mathrm{r}}$ content retained on TFC membrane was much higher than that of CTA, indicating that the SAP was inclined to be adsorbed by TFC membrane. In
AL-FS mode, the propensity of TFC to undergo organic fouling was mainly due to the hydrophobicity of polyamide active layer [39]. In ALDS mode, it was speculated that although TFC had higher electronegativity than CTA as shown in Table 1 , its rougher and more porous support structure probably promoted its much higher adsorption capacity to SAP. As the adsorbate was not tightly combined with the membrane, physical cleaning such as ultrasound in this work could release the connection between SAP and membrane. The hydrophilicity of both layers of CTA enabled the low adsorption capacity to SAP in both modes and all those draw solutions. Although the adsorptive capacity of CTA to SAP (DOC $r+D_{\mathrm{r}} \mathrm{DC}_{\text {loss }}$ ) was much lower than that of TFC, water flux loss of CTA was found close to that of TFC (Fig. 2). It might be attibuted to the fact that some irreversible pollutants were formed in the membrane surface of CTA, and the loss of water flux induced by reversible SAP adsorption was far less than that caused by irreversible pollution.

Furthermore, as shown in Fig. 3(a), in AL-FS mode, the $\mathrm{DOC}_{\mathrm{r}}$ 

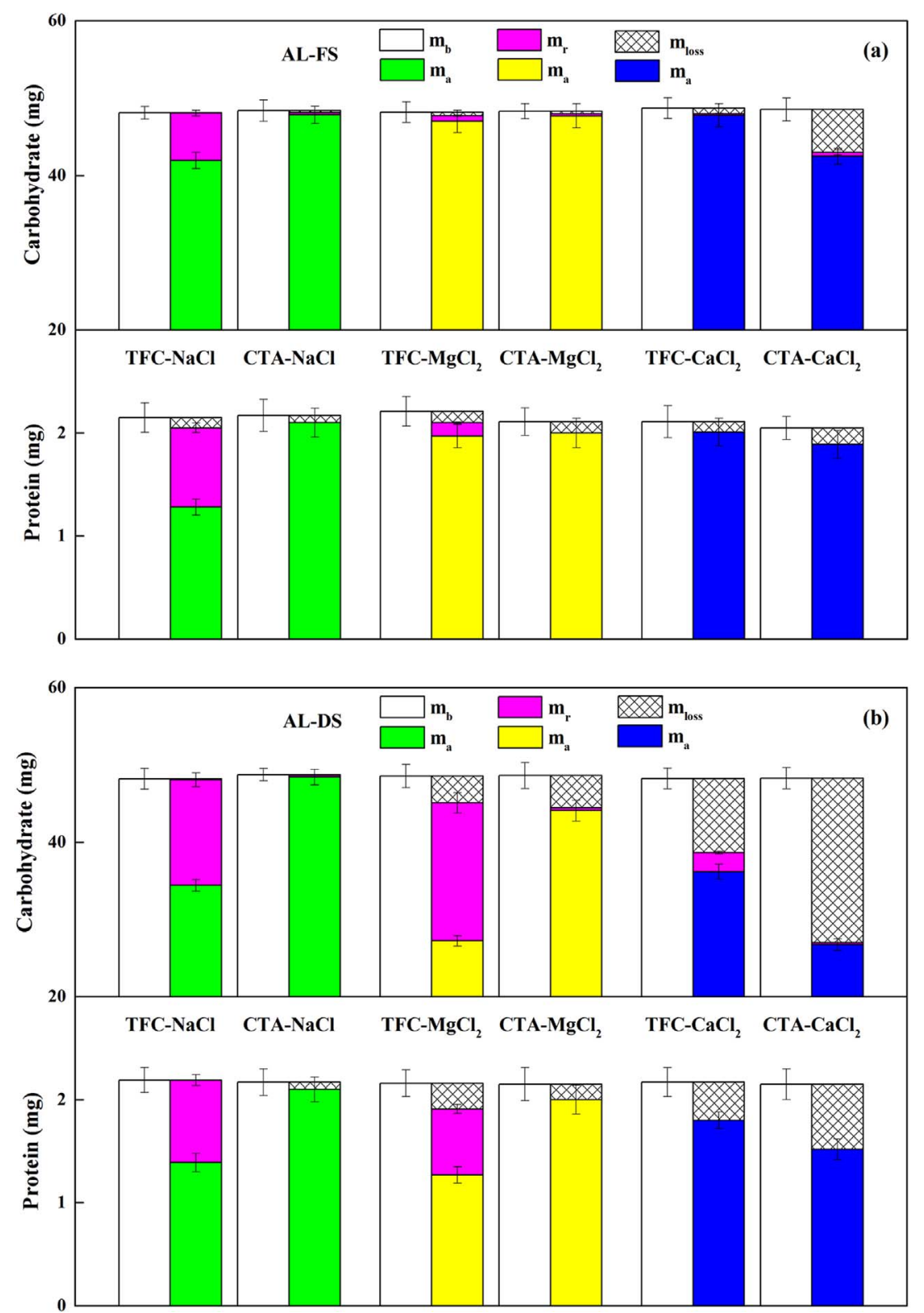

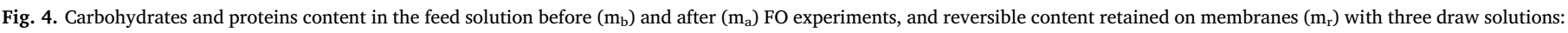
(a) in AL-FS mode, (b) in AL-DS mode.

content adsorbed onto TFC membrane followed the order: $\mathrm{NaCl}>$ $\mathrm{MgCl}_{2}>\mathrm{CaCl}_{2}$. The high adsorbance of SAP with $\mathrm{NaCl}$ was mainly due to the fact that the reverse flux of $\mathrm{NaCl}$ was the highest (Table 1) and positive charge promoted the adsorption of membrane surface to SAP. Unlike $\mathrm{NaCl}$, the reverse flux of $\mathrm{Mg}^{2+}$ and $\mathrm{Ca}^{2+}$ reduced substantially (Table 1), which was consistent with the complexation mechanism showing that $\mathrm{Ca}^{2+}$ could complex with oxygen-containing functional groups of SAP and thus enhancing the formation of irreversible adsorption layer which prevented the reverse diffusion of calcium ions and further adsorption of SAP to membrane surface [40,41]. By contrast, in the mode of AL-DS, $\mathrm{DOC}_{\mathrm{r}}$ content adsorbed on TFC membrane followed the sequence of: $\mathrm{MgCl}_{2}>\mathrm{NaCl}>\mathrm{CaCl}_{2}$. As shown in Fig. 3(b), the amount of SAP adsorbed by $\mathrm{MgCl}_{2}$ exceeded that of $\mathrm{NaCl}$ for TFC membrane in the AL-DS mode. It was probably because the reverse salt flux of $\mathrm{MgCl}_{2}$ greatly increased in this mode (Table 1) that promoting the adsorption of SAP on membrane surface. Moreover, the reversible adsorption layer formed on membrane surface by $\mathrm{MgCl}_{2}$ was insufficient to cause more loss of water flux than $\mathrm{NaCl}$ (Fig. 2). Thus it could not prevent the reverse diffusion of $\mathrm{Mg}^{2+}$ in the porous support layer of TFC and further increase of SAP adsorption.

Theoretically, DOC content followed the equation: $\mathrm{DOC}_{\mathrm{b}}=\mathrm{DOC}_{\mathrm{a}}$ $+\mathrm{DOC}_{\mathrm{r}}+\mathrm{DOC}_{\text {loss }}$ as shown in Eq. (3). It was worth noting that there

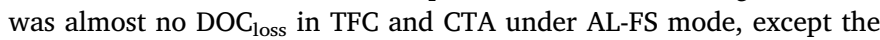
CTA- $\mathrm{CaCl}_{2}$ with extraordinarily unbalanced $\mathrm{DOC}_{\text {loss }}$ of $2.35 \mathrm{mg}$, accounting for $11.8 \%$ of the total initial DOC in the feed solution

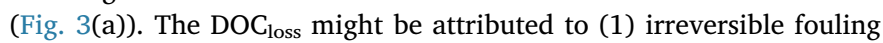
occurred and formed on membrane when $\mathrm{CaCl}_{2}$ was used as draw solution, and (2) insolubles formed on membrane surface which were then washed into feed solution by hydraulic scouring. In AL-DS mode, higher $\mathrm{DOC}_{\text {loss }}$ was found in both membranes with $\mathrm{CaCl}_{2}$. $\mathrm{DOC}_{\text {loss }}$ of the total initial DOC in the feed solution was $8.4 \%$ for TFC membrane, and it was found more significant for CTA-CaCl 2 with the proportion increased to $30.2 \%$ (Fig. 3(b)). However, water flux loss of TFC was higher than CTA with $\mathrm{CaCl}_{2}$, since the irreversible fouling was always found to result in higher water flux loss [23], irreversible fouling should be the main reason for $\mathrm{DOC}_{\text {loss }}$ formed on TFC membrane surface.

As carbohydrates and proteins were major constituents in the SAP of microalgae, the specific contribution of both of them was further 


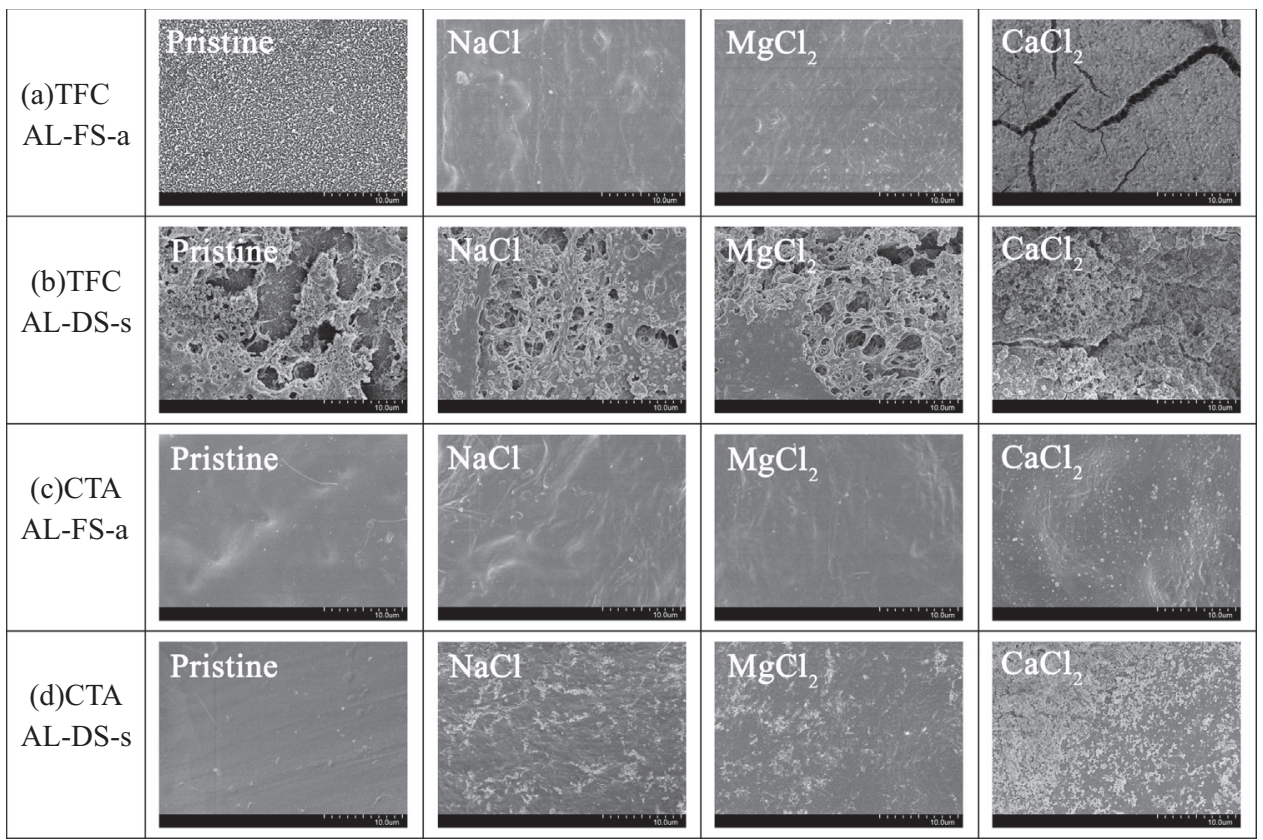

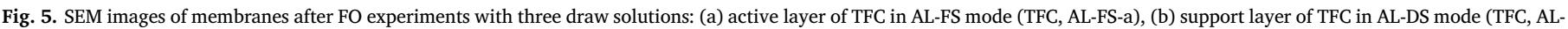
DS-s), (c) active layer of CTA in AL-FS mode (CTA, AL-FS-a), (d) support layer of CTA in AL-DS mode (CTA, AL-DS-s).
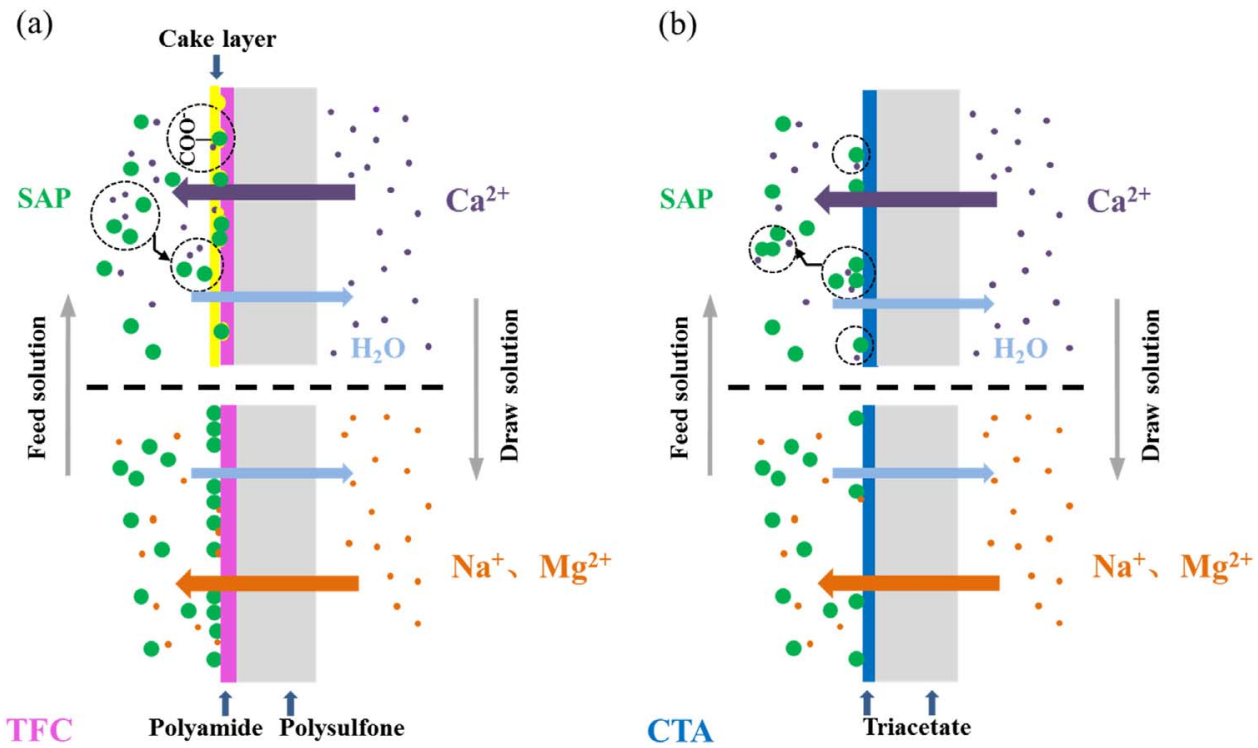

Fig. 6. Schematic of possible membrane fouling mechanism for the FO dewatering of SAP with three draw solutions in AL-FS mode: (a) TFC membrane, (b) CTA membrane.

explored for membrane fouling behavior. Carbohydrates and proteins content in the feed solution before $\left(\mathrm{m}_{\mathrm{b}}\right)$ and after $\left(\mathrm{m}_{\mathrm{a}}\right)$ FO experiments and reversible content retained on membranes $\left(\mathrm{m}_{\mathrm{r}}\right)$ with all those draw solutions in AL-FS and AL-DS orientations were further characterized in Fig. 4. The content on membrane represented reversible part washed from the membrane with ultrasound. On the whole, for both TFC and CTA membranes, carbohydrates proportions of reversible and loss content to the total initial content in the feed solution was consistent with that of the DOC content. Moreover, the mass ratio of carbohydrates to DOC was about 2:1 in this work, even though this ratio was not quite the same as literatures of which the ratio was usually 1:1 [42], it was reasonable that differences in culture conditions caused the increase of carbohydrates content and carbohydrates was the main constituent in membrane fouling. It was clearly to see that compared to the AL-FS mode, the mass ratio of loss content of carbohydrates to the total initial content in the feed solution increased in AL-DS mode with all those three draw solutions, indicating that carbohydrates played an important role in irreversible fouling. As for proteins, although the proportion of proteins components to DOC was only 1:10, reversible and loss content of proteins to the total initial content in the feed solution was similar to that of the DOC content. Besides, the mass ratio of reversible content of proteins to the total initial content in the feed solution increased in AL-DS mode in comparison with AL-FS mode, indicating that proteins might have an impact on membrane reversible fouling.

\subsection{Possible membrane fouling mechanisms for FO-based dewatering of SAP}

The pristine membrane images together with their fouling samples after FO experiments were further characterized by FESEM as shown in Fig. 5, and the schematic of possible membrane fouling mechanism was 
shown in Fig. 6. For pristine membranes, it could be clearly seen that TFC had a relatively much rougher and more porous surface structure in comparison with CTA. When $\mathrm{NaCl}$ and $\mathrm{MgCl}_{2}$ were used as draw solutions, the adsorption layer of SAP was found to attach to the TFC membrane in AL-FS mode (Fig. 6(a)). Although SAP was more likely to be adsorbed by the support layer of TFC in AL-DS mode (Fig. 3), the interaction of SAP with $\mathrm{Na}^{+}$and $\mathrm{Mg}^{2+}$ was not obvious and that did not blocked the porous surface structure of support layer completely. When $\mathrm{CaCl}_{2}$ was used as draw solution for both modes (Fig. 5(a) and (b)), the interaction of SAP from feed solution and reverse salts from draw solution induced a cake layer on the TFC membrane surface (Fig. 6(a)) and thus caused the extraordinary loss of DOC (Fig. 3) and the clogging of channel for water permeation. It indicated that the binding of calcium ions with SAP was more effective than magnesium and sodium ions [5]. It is worth mentioning that there were some cracks in the cake layer (Fig. 5(a)), the formation of which was probably due to the air drying step of SEM pretreatment. Moreover, the rough surface and interaction among $\mathrm{Ca}^{2+}$, SAP and carboxylic acid groups $\mathrm{R}-\mathrm{COOH}$ from the polyamide active layer shown in Fig. 6(a), could fasten the cake layer to membrane surface to avoid the hydraulic scouring of feed solution toward it.

For CTA membrane shown in Fig. 5(c) and (d), the different amount of granular deposits of SAP formed on the membrane surface rather than cake layer was due to the smoother surface which made the SAP adsorbed on CTA easier to be washed into the feed solution by hydraulic scouring (Fig. 6(b)). The amount of granular deposits on membrane surface followed the order: $\mathrm{CaCl}_{2}>\mathrm{MgCl}_{2} \geq \mathrm{NaCl}$. When $\mathrm{NaCl}$ and $\mathrm{MgCl}_{2}$ were used as draw solutions in AL-FS mode, almost no granular deposits of SAP was found to accumulate on membrane surface, resulting that there was no obvious variation of water flux of CTA in this mode (Fig. 1(a)). The presence of $\mathrm{Ca}^{2+}$ led to deposition of particles on the surface of membrane (Fig. 6(b)) and increase of water flux loss. Due to rougher membrane surface facing to feed and higher reverse salt fluxes in AL-DS mode, the reverse salts and SAP were interacted to settle and fill the pores of support layer partly, aggravating the membrane fouling, and thus the more significant flux decline (Fig. 1(b)). The results showed that a smoother membrane surface and lower reverse salt fluxes would be contributed to the reduction of adsorption or deposition of SAP.

The above discussion revealed that FO membrane fouling was strongly affected by membrane surface chemistry and draw solution chemistry. TFC membranes containing carboxyl acid groups were easier to aggravate membrane fouling for the presence of $\mathrm{Ca}^{2+}$ in the draw solution. The interaction between SAP and reverse diffused $\mathrm{Ca}^{2+}$ also made a contribution to membrane fouling. The results showed that draw solutions of $\mathrm{NaCl}$ and $\mathrm{MgCl}_{2}$ showing great water flux and high fouling resistance should be appropriate selections for microalgae dewatering. Fabrication of anti-fouling forward osmosis membranes should be focused on to propel the integration of forward osmosis with traditional field of microalgae dewatering.

\section{Conclusions}

For the dewatering of SAP, the TFC membrane exhibited higher water permeability but more loss of water flux in comparison with CTA. The SAP was inclined to be adsorbed by TFC membrane while adsorbate was easier to be cleaned by physical cleaning. By contrast, the pollutants accumulated on membrane surface of CTA were much more irreversible. Compared with AL-FS mode, carbohydrates of SAP were found to play an important role in membrane irreversible fouling while proteins components were related to membrane reversible fouling in AL-DS mode. The most severe membrane fouling for $\mathrm{CaCl}_{2}$ was attributed mainly to the interaction between SAP from feed solution and calcium cations from draw solution, which induced the formation of cake layer on the surface of TFC membrane whereas irreversible granular deposits of SAP were found accumulated on the CTA membrane surface.

\section{Acknowledgments}

This work was supported by National Key Research and Development Program of China (2016YFB0601002-04), Important National Science \& Technology Specific Projects (2014ZX07101-01204) and the Science \& Technology Projects of Water Resources Department of Jiangxi Province (KT201502).

\section{References}

[1] C.S. Jones, S.P. Mayfield, Algae biofuels: versatility for the future of bioenergy, Curr. Opin. Biotechnol. 23 (2012) 346-351.

[2] S. Zhao, L. Zou, C.Y. Tang, D. Mulcahy, Recent developments in forward osmosis: opportunities and challenges, J. Membr. Sci. 396 (2012) 1-21.

[3] R. Chen, R. Li, L. Deitz, Y. Liu, R.J. Stevenson, W. Liao, Freshwater algal cultivation with animal waste for nutrient removal and biomass production, Biomass Bioenergy 39 (2012) 128-138.

[4] S.P. Cuellar-Bermudez, G.S. Aleman-Nava, R. Chandra, J.S. Garcia-Perez, J.R. Contreras-Angulo, G. Markou, K. Muylaert, B.E. Rittmann, R. Parra-Saldivar, Nutrients utilization and contaminants removal. A review of two approaches of algae and cyanobacteria in wastewater, Algal Res. 24 (2017) 438-449.

[5] M. Larronde-Larretche, X. Jin, Microalgal biomass dewatering using forward osmosis membrane: influence of microalgae species and carbohydrates composition, Algal Res. 23 (2017) 12-19.

[6] N. Uduman, Y. Qi, M.K. Danquah, G.M. Forde, A. Hoadley, Dewatering of microalgal cultures: a major bottleneck to algae-based fuels, J. Renew. Sustain. Energy 2 (2010) 012701.

[7] R. Bhave, T. Kuritz, L. Powell, D. Adcock, Membrane-based energy efficient dewatering of microalgae in biofuels production and recovery of value added coproducts, Environ. Sci. Technol. 46 (2012) 5599-5606.

[8] T. Cai, S.Y. Park, Y. Li, Nutrient recovery from wastewater streams by microalgae: status and prospects, Renew. Sustain. Energy Rev. 19 (2013) 360-369.

[9] M.R. Bilad, H.A. Arafat, I.F. Vankelecom, Membrane technology in microalgae cultivation and harvesting: a review, Biotechnol. Adv. 32 (2014) 1283-1300.

[10] M. Shekhar, A. Shriwastav, P. Bose, S. Hameed, Microfiltration of algae: impact of algal species, backwashing mode and duration of filtration cycle, Algal Res. 23 (2017) 104-112.

[11] X. Sun, C. Wang, Y. Tong, W. Wang, J. Wei, A comparative study of microfiltration and ultrafiltration for algae harvesting, Algal Res. 2 (2013) 437-444.

[12] S.E. Kwan, E. Bar-Zeev, M. Elimelech, Biofouling in forward osmosis and reverse osmosis: measurements and mechanisms, J. Membr. Sci. 493 (2015) 703-708.

[13] M.L. Gerardo, D.L. Oatley-Radcliffe, R.W. Lovitt, Integration of membrane technology in microalgae biorefineries, J. Membr. Sci. 464 (2014) 86-99.

[14] P. Praveen, K.C. Loh, Nitrogen and phosphorus removal from tertiary wastewater in an osmotic membrane photobioreactor, Bioresour. Technol. 206 (2016) 180-187.

[15] P. Praveen, J.Y. Heng, K.C. Loh, Tertiary wastewater treatment in membrane photobioreactor using microalgae: comparison of forward osmosis \& microfiltration, Bioresour. Technol. 222 (2016) 448-457.

[16] M. Xie, D.N. Long, W.E. Price, M. Elimelech, Toward resource recovery from was tewater: extraction of phosphorus from digested sludge using a hybrid forward osmosis-membrane distillation process, Environ. Sci. Technol. Lett. 1 (2014) 191-195.

[17] R.W. Holloway, A.E. Childress, K.E. Dennett, T.Y. Cath, Forward osmosis for concentration of anaerobic digester centrate, Water Res. 41 (2007) 4005-4014.

[18] V. Sant'Anna, L.D.F. Marczak, I.C. Tessaro, Membrane concentration of liquid foods by forward osmosis: process and quality view, J. Food Eng. 111 (2012) 483-489.

[19] J. Huang, Q. Long, S. Xiong, L. Shen, Y. Wang, Application of poly (4-styr enesulfonic acid-co-maleic acid) sodium salt as novel draw solute in forward osmosis for dye-containing wastewater treatment, Desalination 421 (2017) 40-46.

[20] J. Heikkinen, H. Kyllönen, E. Järvelä, A. Grönroos, C.Y. Tang, Ultrasound-assisted forward osmosis for mitigating internal concentration polarization, J. Membr. Sci. 528 (2017) 147-154.

[21] T.Y. Cath, A.E. Childress, M. Elimelech, Forward osmosis: principles, applications, and recent developments, J. Membr. Sci. 281 (2006) 70-87.

[22] Y. Gu, Y.-N. Wang, J. Wei, C.Y. Tang, Organic fouling of thin-film composite polyamide and cellulose triacetate forward osmosis membranes by oppositely charged macromolecules, Water Res. 47 (2013) 1867-1874.

[23] R. Honda, W. Rukapan, H. Komura, Y. Teraoka, M. Noguchi, E.M. Hoek, Effects of membrane orientation on fouling characteristics of forward osmosis membrane in concentration of microalgae culture, Bioresour. Technol. 197 (2015) 429-433.

[24] B. Biddanda, R. Benner, Carbon, nitrogen, and carbohydrate fluxes during the production of particulate and dissolved organic matter by marine phytoplankton, Limnol. Oceanogr. 42 (1997) 506-518.

[25] N. Her, G. Amy, H.R. Park, M. Song, Characterizing algogenic organic matter (AOM) and evaluating associated NF membrane fouling, Water Res. 38 (2004) 1427-1438.

[26] X. Ming, E. Barzeev, S.M. Hashmi, D.N. Long, M. Elimelech, Role of reverse divalent cation diffusion in forward osmosis biofouling, Environ. Sci. Technol. 49 (2015) $13222-13229$.

[27] M. Larronde-Larretche, X. Jin, Microalgae ( Scenedesmus obliquus) dewatering 
using forward osmosis membrane: influence of draw solution chemistry, Algal Res. 15 (2016) 1-8.

[28] Y.T. Chiou, M.L. Hsieh, H.H. Yeh, Effect of algal extracellular polymer substances on UF membrane fouling, Desalination 250 (2010) 648-652.

[29] T. Steinhauer, M. Marx, K. Bogendörfer, U. Kulozik, Membrane fouling during ultraand microfiltration of whey and whey proteins at different environmental conditions: the role of aggregated whey proteins as fouling initiators, J. Membr. Sci. 489 (2015) 20-27.

[30] A. Tiraferri, N.Y. Yip, A.P. Straub, S. Romero-Vargas Castrillon, M. Elimelech, A method for the simultaneous determination of transport and structural parameters of forward osmosis membranes, J. Membr. Sci. 444 (2013) 523-538.

[31] X. Zhao, H.Y. Hu, S.M. Liu, F. Jiang, X.L. Shi, L.I. Mingtang, X.U. Xueqiao, Improvement of the assimilable organic carbon (AOC) analytical method for reclaimed water, Front. Environ. Sci. Eng. 7 (2013) 483-491.

[32] M. Dubois, K.A. Gilles, J.K. Hamilton, P.A. Rebers, F. Smith, Colorimetric method for determination of sugars and related substances, Anal. Chem. 28 (1955) 350-356.

[33] B. Frølund, T. Griebe, P.H. Nielsen, Enzymatic activity in the activated-sludge floc matrix, Appl. Microbiol. Biotechnol. 43 (1995) 755-761.

[34] N. Bolong, A.F. Ismail, M.R. Salim, D. Rana, T. Matsuura, Development and characterization of novel charged surface modification macromolecule to polyethersulfone hollow fiber membrane with polyvinylpyrrolidone and water, J. Membr. Sci. 331 (2009) 40-49.
[35] J. Ren, J.R. Mccutcheon, A new commercial thin film composite membrane for forward osmosis, Desalination 343 (2014) 187-193.

[36] M. Elimelech, W.H. Chen, J.J. Waypa, Measuring the zeta (electrokinetic) potential of reverse osmosis membranes by a streaming potential analyzer, Desalination 95 (1994) 269-286.

[37] V. Parida, H.Y. Ng, Forward osmosis organic fouling: effects of organic loading, calcium and membrane orientation, Desalination 312 (2013) 88-98.

[38] Q. Li, Z. Xu, I. Pinnau, Fouling of reverse osmosis membranes by biopolymers in wastewater secondary effluent: role of membrane surface properties and initial permeate flux, J. Membr. Sci. 290 (2007) 173-181.

[39] V. Freger, J. Gilron, S. Belfer, TFC polyamide membranes modified by grafting of hydrophilic polymers: an FT-IR/AFM/TEM study, J. Membr. Sci. 209 (2002) 283-292.

[40] F. Bruni, S. Imberti, R. Mancinelli, M.A. Ricci, Aqueous solutions of divalent chlorides: ions hydration shell and water structure, J. Chem. Phys. 136 (2012) $137-148$.

[41] E.M. Hoek, M. Elimelech, Cake-enhanced concentration polarization: a new fouling mechanism for salt-rejecting membranes, Environ. Sci. Technol. 37 (2003) 5581-5588.

[42] L.-L. Zhuang, Y.-H. Wu, V.M.D. Espinosa, T.-Y. Zhang, G.-H. Dao, H.-Y. Hu, Soluble Algal Products (SAPs) in large scale cultivation of microalgae for biomass/bioenergy production: a review, Renew. Sustain. Energy Rev. 59 (2016) 141-148. 